\title{
NEW PROTONEMURA (S. L.) FROM NEPAL (PLECOPTERA; NEMOURIDAE)*
}

\author{
BY P. P. HARPER
}

Département des Sciences biologiques

Université de Montréal

C. P. 6r28, Montréal, Qué.

Described below are the stoneflies of the genus Protonemura (Nemouridae) collected in 1967 by the Canadian Nepal Expedition organized by the Entomological Research Institute of the Canada Department of Agriculture in Ottawa. The genus Protonemura is understood here in its widest sense (sensu lato) as used by Kimmins (1946, 1950) and Aubert (1967); the genus is obviously in need of a revision as it contains a wide assemblage of forms some of which bear larval gills and some which do not. The species considered here are apparently gill-less as far as can be ascertained from the adults.

The material examined comes from six localities: Godavari at altitudes of $5000 \mathrm{ft}$ and $6000 \mathrm{ft}$, Bhurunche at an altitude of $8500-$ $9500 \mathrm{ft}$, and four localities known only from their geographical coordinates and altitudes: $27^{\circ} 56^{\prime} \mathrm{N}, 85^{\circ} \mathrm{OO}$ E at $9900 \mathrm{ft}$ and $10100 \mathrm{ft}$, $27^{\circ} 57^{\prime} \mathrm{N}, 84^{\circ} 59^{\prime} \mathrm{E}$ at Ioroo $\mathrm{ft}, 27^{\circ} 58^{\prime} \mathrm{N}, 85^{\circ} \mathrm{Oo} 0^{\prime} \mathrm{E}$ at III IOo ft, and $28^{\circ} \mathrm{Oo}^{\prime} \mathrm{N}, 85^{\circ} \mathrm{Oo} / \mathrm{E}$ at $9900 \mathrm{ft}$. Most of the specimens were collected in Malaise traps and therefore the collection dates indicate the period between visits to the traps.

All the specimens are preserved in alcohol and are deposited in the Canadian National Collection of Insects in Ottawa. The drawings have been prepared from cleared specimens. Only the species represented by male specimens have been named, the others have been designated by letters to prevent useless future synonymy.

\section{Protonemura mira, n. sp.}

Figures $\mathrm{I}-4$

Length of body II $\left(\sigma^{x}\right)-\mathrm{I} 4($ o $) \mathrm{mm}$, to tips of wings $16\left(\sigma^{x}\right)$ 19 ( 9 ) $\mathrm{mm}$.

General coloration dark reddish brown; antennae black; anterior and lateral margins of pronotum light; wings uniformly brown; legs brown, tarsi and distal end of femora darkened; metafemora also with a subapical dark ring. Abdomen mostly membranous except for the genital segments and a pair of sclerotized tergal plates on each segment in the male. Genitalia reddish brown.

*Manuscript received by the editor November 18, 1974. 

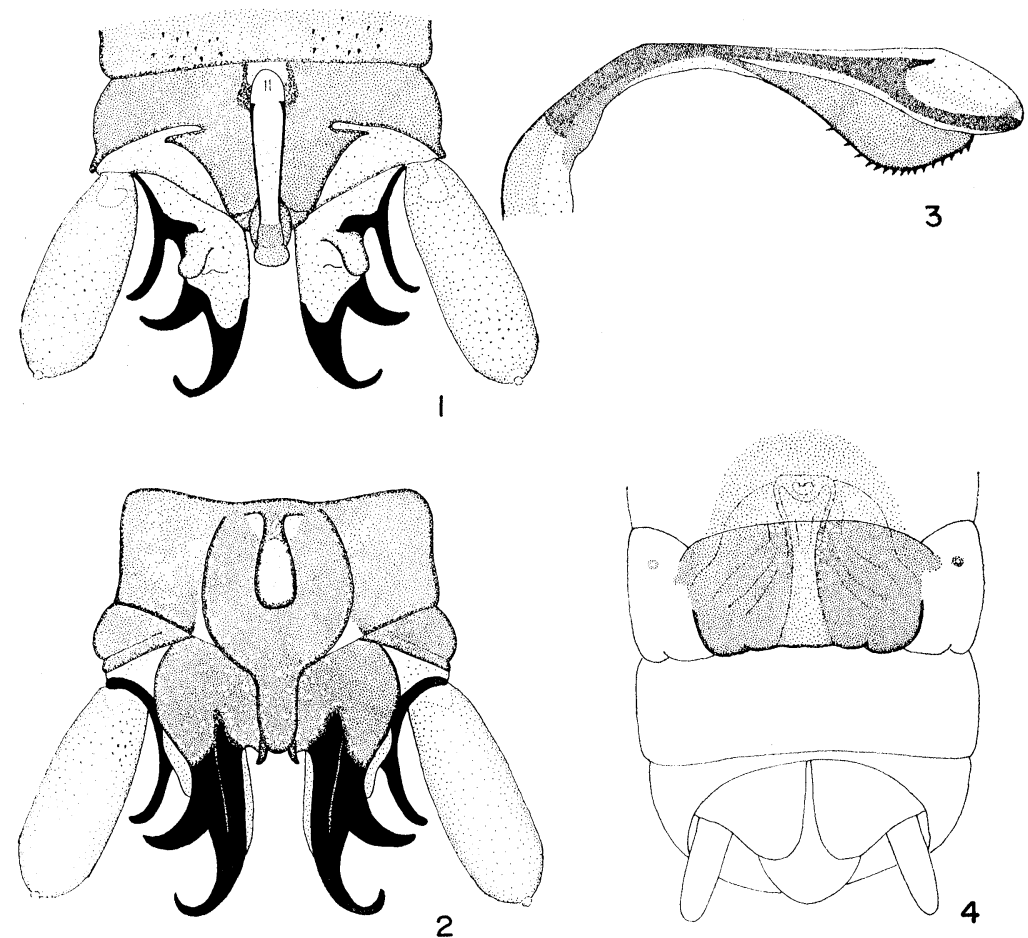

Figures 1-4: Protonemura mira Harper, n. sp. 1. Terminal segments of male with paraprocts slightly pulled out (dorsal). 2. The same (ventral). 3. Epiproct (lateral). 4. Terminal segments of female (ventral).

Male genitalia: median lobe of sternum IX long and narrow, ventral vesicle short. Paraproct: median lamella small, slightly curved, extending just beyond sternum IX; subanal plate wide, its process forming two dark heavy hooks; subanal vesicle short; external appendage finger-like, heavily sclerotized and gradually curved. Cerci long and membranous. Tergum IX with a few spinules on its posterior margin. Epiproct long and slender with an expanded tip bearing a double row of ventral spinules.

Female genitalia: subgenital plate sclerotized, wide, with rounded corners, but not produced posteriorly. Vaginal structures as in Figure 4, somewhat reminiscent of Protonemura A of Aubert (1967, Fig. 99), but the subgenital plates are different. 
Holotype: $\sigma^{x}$, Godavari, $6000 \mathrm{ft}, \mathrm{I} 7-20$. VII. 1967 (CNC type no. 13430). Allotype: $q$, and paratype: $q$, same data.

Diagnosis: $P$. mira clearly belongs to the $P$. indica Kimmins group as defined by Aubert (1967); the shape of the process of the paraprocts of the male and the subgenital plate as well as the vaginal structures of the female will easily separate mira from the other known species of the group.

\section{Protonemura godavariensis, n. sp. \\ Figures 5-8}

Length of body IO-I $3 \mathrm{~mm}$, to tips of wings $13-15 \mathrm{~mm}$.

General coloration dark brown. Wings uniformly brown. Legs brownish, femora with two subapical dark bands. Abdomen brownish, genitalia dark brown.
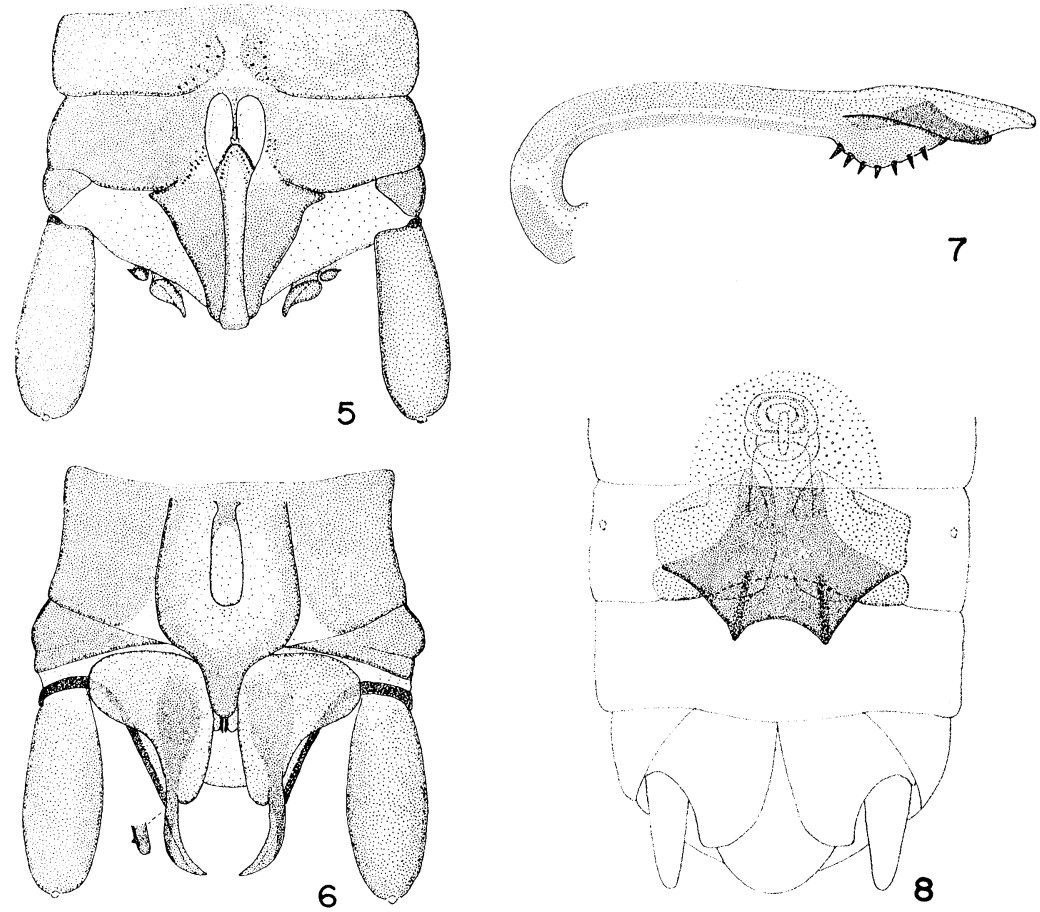

Figures 5-8: Protonemura godavariensis Harper, n. sp. 5. Terminal segments of male (dorsal). 6. The same (ventral). 7. Epiproct (lateral). 8. Terminal segments of female (ventral). 
Male genitalia: median lobe of sternum IX narrow and of moderate length; ventral vesicle reaching beyond middle of sternum. Paraproct: median lamella short and pointed, heavily sclerotized; subanal plate wide, triangular, with broadly rounded angles; distal process forming a long curved trough-like appendage; external appendage finger-like, heavily sclerotized externally and bearing a subapical lateral tooth; the external appendage extends just beyond the subanal plate. Cerci long and membranous. Terga IX and X bearing small fields of spinules. Epiproct long and slender, its tip expanded laterally and bearing ventrally a short double row of heavy teeth.

Female genitalia: subgenital plate well sclerotized, prolonged posteriorly into a trapezoidal lobe which is broadly and regularly emarginate. Vaginal structures as in Figure 8.

Holotype: $0^{\top}$, Godavari, $5000 \mathrm{ft}, 20-23 . V I I .1967$ (CNC type no. I343I) ; allotype: $q$, same data; paratypes: $\sigma^{n}$, + , same locality, 20.VII.-4.VIII. 1967 .

Diagnosis: as the preceding species, $P$. godavariensis belongs to the $P$. indica group. The trough-like process of the subanal lobe of the male as well as the vaginal structures of the female are good diagnostic characters. The species is very close to $P$. assami Aubert and may eventually prove to be the same.

\section{Protonemura funicula, n. sp.}

Figures 9-I I

Length of body, I I-I $2 \mathrm{~mm}$, to tips of wings, I8-19 mm.

General coloration brown; head and disk of pronotum dark brown. Wings clear, veins of the front wings marginated with brown. Legs banded: femora with a median and distal dark band, tibiae narrowly darkened at base and darkened again distally, tarsi dark. Abdomen mostly membranous except the genital segments; in the male a pair of small ventral sclerites and a pair of larger dorsal sclerites are borne at the base of each abdominal segment.

Male genitalia: sternum IX long with a short rounded median lobe; ventral vesicle large reaching three quarters of the length of the sternum. Paraproct: median lamella narrow; subanal plate partly membranous, irregularly triangular, prolonged distally into a heavily sclerotized process which is slightly recurved dorsally; this process is pointed apically and bears a sharp subterminal spine; ex- 


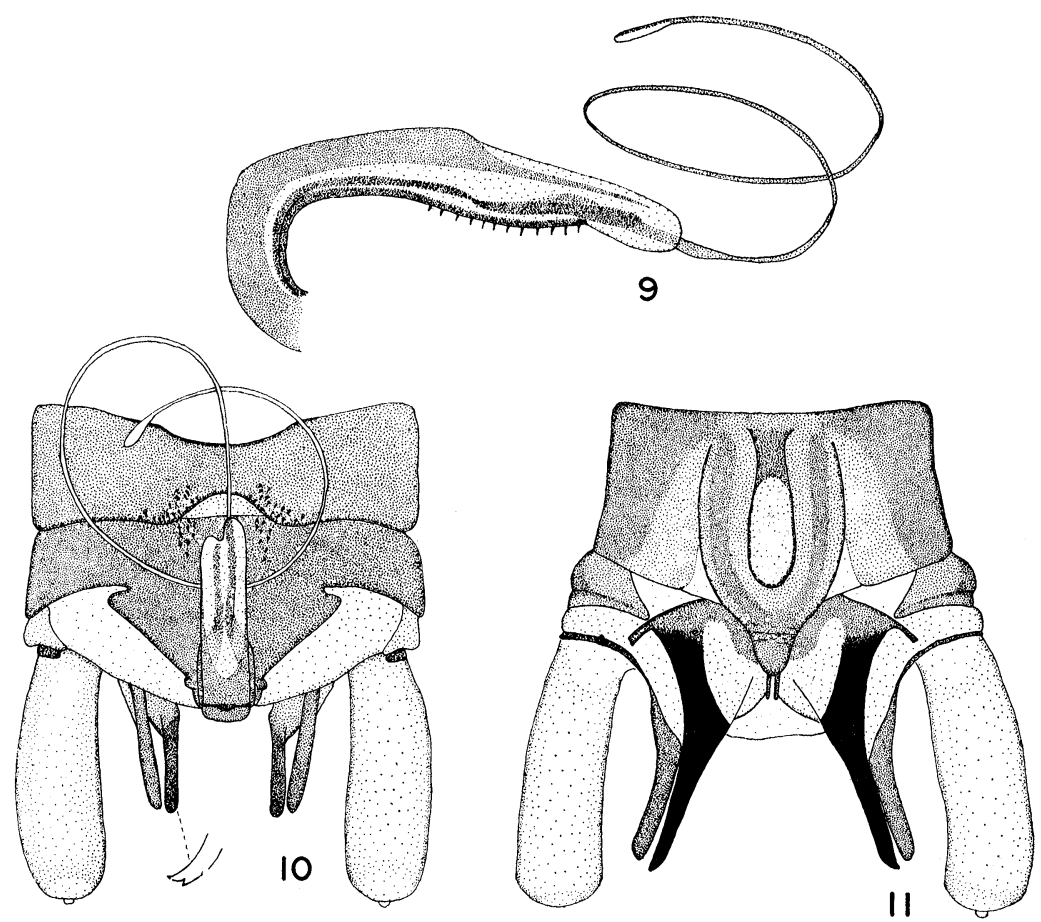

Figures 9-11: Protonemura funicula Harper, n. sp. 9. Epiproct (lateral). 10. Terminal segments of male (dorsal). 11. The same (ventral).

ternal appendage moderately sclerotized, finger-like, and reaching out as far as the process. Cerci long and membranous. Terga IX and $X$ with small median fields of spinules. Epiproct narrow and flat, asymmetrical distally and prolonged by a very long whip-like process.

Female: unknown.

Holotype: $0^{\top}, 27^{\circ} 57^{\prime} \mathrm{N}, 84^{\circ} 59^{\prime} \mathrm{E}$, ioroo ft, 26-3r.V.I967 (CNC type no. I3432) ; paratypes: $\sigma^{\circ}, 27^{\circ} 56^{\prime} \mathrm{N}, 85^{\circ} \mathrm{Oo}$ ' E, Iогоo ft, $23-29$.

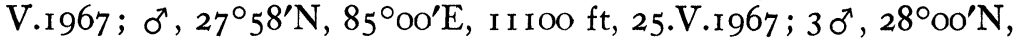
$85^{\circ} \mathrm{Oo}$ 'E, $9900 \mathrm{ft}, 27 . V .-22 . V I .1967$.

Diagnosis: P. funicula can be placed in the P. filigera (Kimmins) group of Aubert (1967). The shape of the subanal lobes and the particularly long appendage of the epiproct are distinctive. 


\section{Protonemura adunca, n. sp.}

Figures I2-14

Length of body IO-I I mm, to tips of wings, I3-I $4 \mathrm{~mm}$.

General coloration dark brown; antennae and disk of pronotum nearly black. Wings amber, veins darker. Legs particularly the hind pair banded; femora with a median and a distal band. Abdomen membranous except the genital segments; in the male there is also a pair of small sclerites at the base of each tergum.

Male genitalia: sternum IX broadly pentagonal, prolonged into a long and tapering median lobe; this median lobe bears distally an apical expansion which is outturned at a right angle from the lobe and forms a beak-like extension ending in two sharp points. Paraproct: median lamella narrow and rounded apically; subanal plate sclerotized at base, divided distally into three lobes, the inner lobe short and rounded, the intermediate lobe membranous, and the outer lobe long and digitiform, fused laterally with the external appendage; external appendage fused with subanal lobe for most of its length, terminating distally in a beak-like point. Cerci long, membranous, and expanded slightly at tips. Tergum IX emarginate centrally, the emargination bearing short spinules. Tergum $\mathrm{X}$ excavated anteriorly, and prolonged into two short median lobes covered with spinules. Epiproct cylindrical, asymmetrical beyond middle, and terminating in a short curved lobe; a short irregular group of spinules at base of epiproct.

Female: unknown.

Holotype: $\sigma^{\top}, 27^{\circ} 57^{\prime} \mathrm{N}, 84^{\circ} 59^{\prime} \mathrm{E}$, Ioroo ft, 26-31.V.I967, (CNC type no. I 3433 ); paratypes: $\sigma^{\top}$, same data; $\sigma^{x}, 27^{\circ} 5^{\prime} \mathrm{N}, 85^{\circ} \mathrm{Oo}$ E, I I IOO ft, I8.V.I $967 ; 40^{\top}, 28^{\circ} \mathrm{Oo}^{\prime} \mathrm{N}, 85^{\circ} \mathrm{Oo} \mathrm{O}^{\prime} \mathrm{E}$, $9900 \mathrm{ft}, 2 \mathrm{I} . \mathrm{V} .-22 . V I$. I967; $2 \sigma^{7}$, Bhurunche, 8500-9500 ft, 23.V.I967.

Diagnosis: $P$. adunca probably fits into the $P$. filigera group on the basis of its epiproct. The shape of the distal end of the median lobe of sternum IX is quite distinctive and unique.

\section{Protonemura mastigophora, n. sp.} Figures I 5-I7

Length of body Io $\mathrm{mm}$, to tips of wings, $13 \mathrm{~mm}$.

General coloration dark brown. Head nearly black (antennae missing). Wings brownish with some darker clouds. Legs banded, particularly the hind pair; femora with a dark distal band and a paler median one. Abdomen membranous except for the genital segments. 

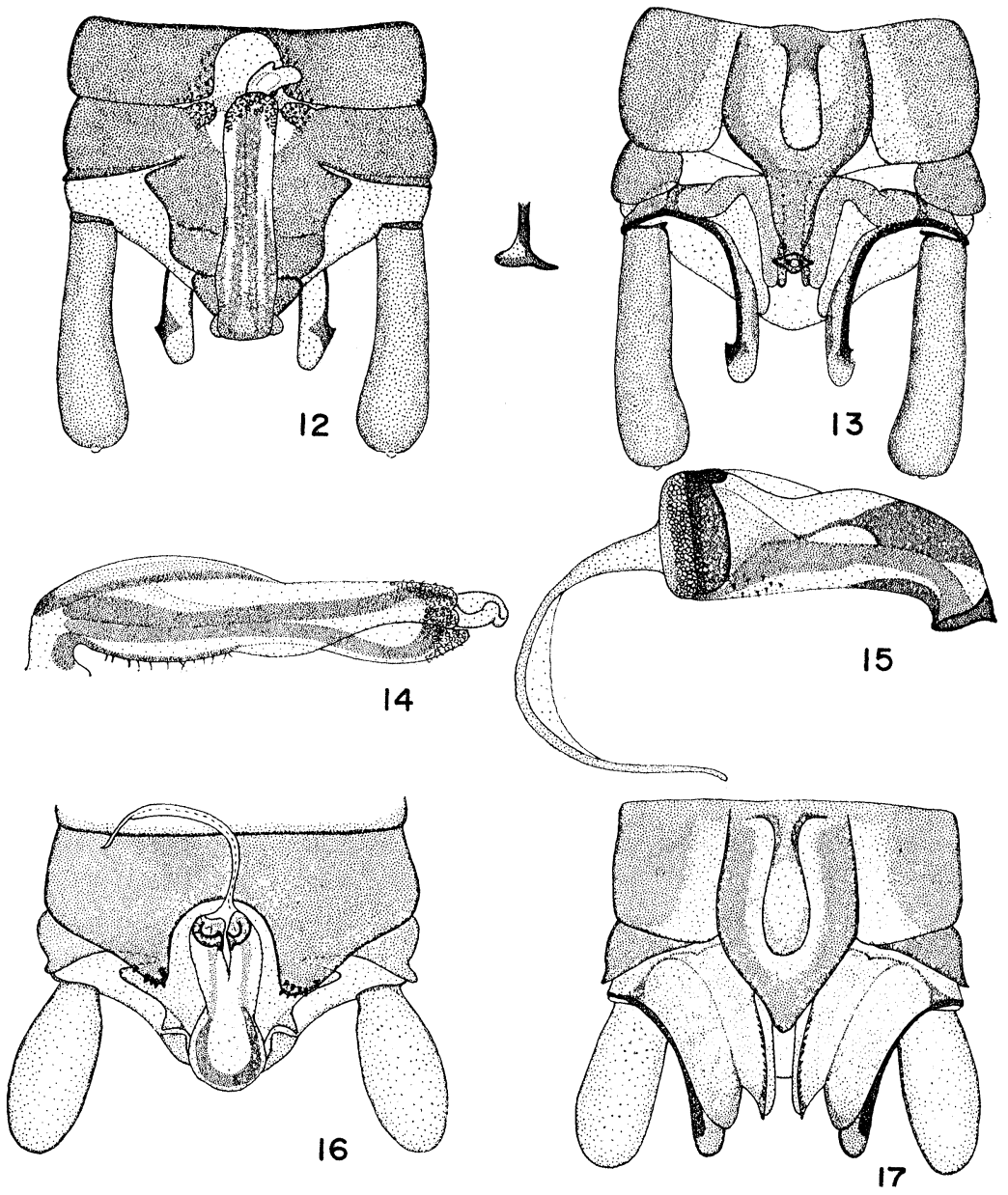

Figures 12-14: Protonemura adunca Harper, n. sp. 12. Terminal segments of male (dorsal). 13. The same (ventral). Figures 15-17: Protonemura mastigophora Harper, n. sp. 15. Epiproct (lateral). 16. Terminal segments of male (dorsal). 17. The same (ventral). 
Male genitalia: sternum IX long and pentagonal; median lobe short and inconspicuous; ventral vesicle large. Paraproct: median lamella long, thin, and extending backwards as far as the subanal plate; subanal plate terminating in two finger-like lobes, a shorter median lobe, and a larger lateral lobe; external appendage fused to lateral lobe of subanal plate and extending three quarters of its length. Tergum IX produced posteriorly into two asymmetrical lobes separated by a large median excavation; each lobe bears a distal patch of spines. Tergum $X$ normal. Epiproct short and stocky, remarkably asymmetrical, and bearing a terminal whip-like appendage.

Female: unknown.

Holotype: $0^{\top}, 27^{\circ} 56^{\prime} \mathrm{N}, 85^{\circ} \mathrm{Oo}$ 'E, гогоo ft, 23-29.V.1967 (CNC type no. I3493).

Diagnosis: another member of the $P$. filigera group, $P$. mastigophora is close to the species filigera (Kimmins 1946), parafiligera Aubert 1967 and metafiligera Aubert 1967. It can be best distinguished from the others by the shape and the sclerotizations of its epiproct; these are not as well produced in $P$. filigera the species it resembles most; Kimmins' (1946) drawing shows no detail of the inner structure of the epiproct, but a specimen in the United States National Museum (det. R. W. Baumann) does not possess the structures described here for mastigophora.

\section{Protonemura A}

Figure 18

In general structure and coloration, this female agrees with $P$. funicula and $P$. adunca; it could be the female of either.

Female genitalia: the subgenital plate is very slightly trilobed. Vaginal structures as in Figure 18.

Material examined: $ᄋ, 27^{\circ} 56^{\prime} \mathrm{N}, 85^{\circ} \mathrm{Oo}{ }^{\prime} \mathrm{E}, 9900 \mathrm{ft}, 23-29 . V .1967$;

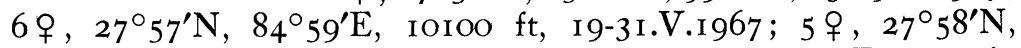
$85^{\circ} \mathrm{Oo}$ E, I I IOO ft, 8-24.VI.I967; 4 우, $28^{\circ} \mathrm{Oo}$ N, $85^{\circ} \mathrm{Oo}$ ' E, $9900 \mathrm{ft}$, I4.V.-22.VI.1967.

\section{Protonemura B}

Figure 19

Total length $10 \mathrm{~mm}$, to tips of wings, $13 \mathrm{~mm}$.

General coloration brown. Wings uniformly amber. Legs banded in the usual manner. 

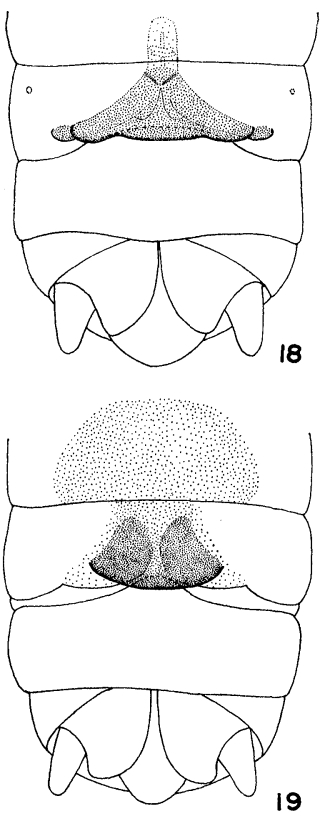
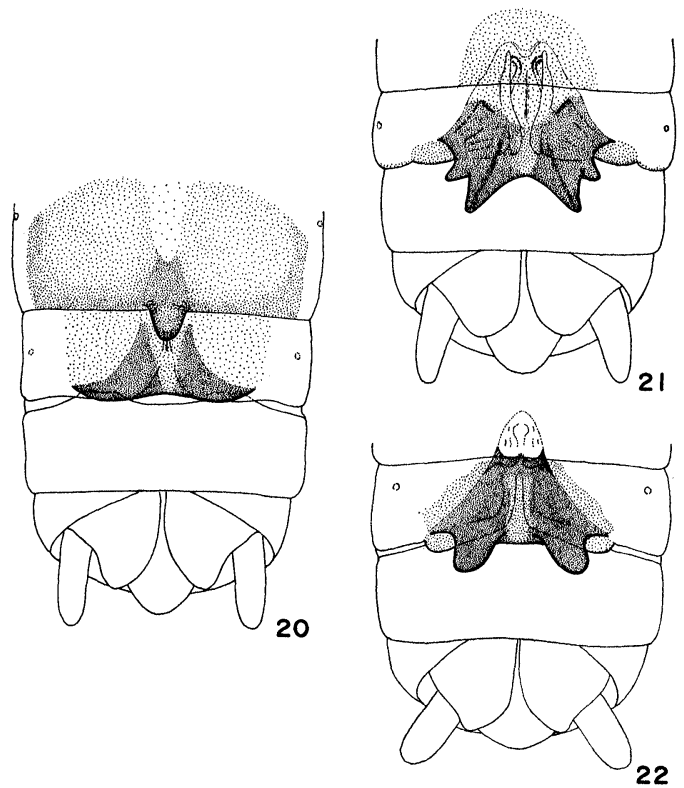

Figures 18-22: Terminal segments of unassociated females (ventral). 18. Protonemura A. 19 Protonemura B. 20. Protonemura C. 21. Protonemura D. 22. Protonemura E.

Female genitalia: subgenital plate small, and rounded posteriorly. Sternum VII sclerotized medially. Vaginal structures indistinct.

Material examined: 우 , $28^{\circ} \mathrm{Oo}^{\prime} \mathrm{N}, 85^{\circ} \mathrm{Oo} \mathrm{O}^{\prime} \mathrm{E}, 9900 \mathrm{ft}, 27 . \mathrm{V} .-22 . \mathrm{VI}$. I 967.

\section{Protonemura $\mathrm{C}$}

Figure 20

Total length I I-I $2 \mathrm{~mm}$, to tips of wings, I 5-16 mm.

General coloration brown. Wings yellowish-brown, veins dark brown, marginated with brown. Legs brown with a subterminal white band.

Female genitalia: subgenital plate short, slightly bilobed. Sternum VII heavily sclerotized bearing an important posterior nipple-like protuberance. Vaginal structures indistinct.

Material examined: 22 ㅇ, $27^{\circ} 58^{\prime} \mathrm{N}, 85^{\circ} \mathrm{OO}$ E, I I IOO ft, 2-24.VI. I967. 


\section{Protonemura D}

Figure 21

Total length $15 \mathrm{~mm}$, to tips of wings, $18 \mathrm{~mm}$.

General coloration dark brown. Wings blackish. Pro- and mesofemora light brown with an apical darkening, meta-femora brown with a subapical light ring.

Female genitalia: sternum VII lightly sclerotized medially. Subgenital plate forming posteriorly two pairs of lobes separated by a wide emargination. Vaginal structures very characteristic, as in Figure $2 \mathrm{I}$.

Material examined: 2 오, Godavari, $6000 \mathrm{ft}$, 14-20.VII.1967.

Remarks: This species evidently belongs to the $P$. indica group; it can be separated from $P$. indica Kimmins 1946 and $P$. quadridentata Kimmins 1950 (see Figures I8, 29\& 30 in Aubert 1967) the species it resembles most by the shape of its vaginal structures and by its medially pigmented (and sclerotized) seventh sternum.

\section{Protonemura E}

Figure 22

Total length $\mathrm{I} 3 \mathrm{~mm}$, to tips of wings, $16 \mathrm{~mm}$.

General coloration similar to that of Protonemura D.

Female genitalia: subgenital plate produced into two rounded posterolateral lobes. Vaginal structures very distinctive, as in Figure 22.

Material examined: 우, Godavari, 6000 ft, i7-20.VII.1967.

\section{Acknowledgments}

I thank Mr. J. E. H. Martin of the Canada Department of Agriculture in Ottawa for allowing me to study this material and Dr. R. W. Baumann of the United States National Museum for the loan of material and the comparison of specimens.

\section{REFERENCES}

AuberT, J.

1967. Les Nemouridae de l'Assam (Plécoptères). Mitt. Schweiz. Entomol. Ges. 39: 209-253.

Kimmins, D. E.

1946. New species of Himalayan Plecoptera. Ann. Mag. Nat. Hist. (11) $13: 721-740$.

1950. Some Assamese Plecoptera, with descriptions of new species of Nemouridae. Ibid. (12) $3:$ 194-209. 

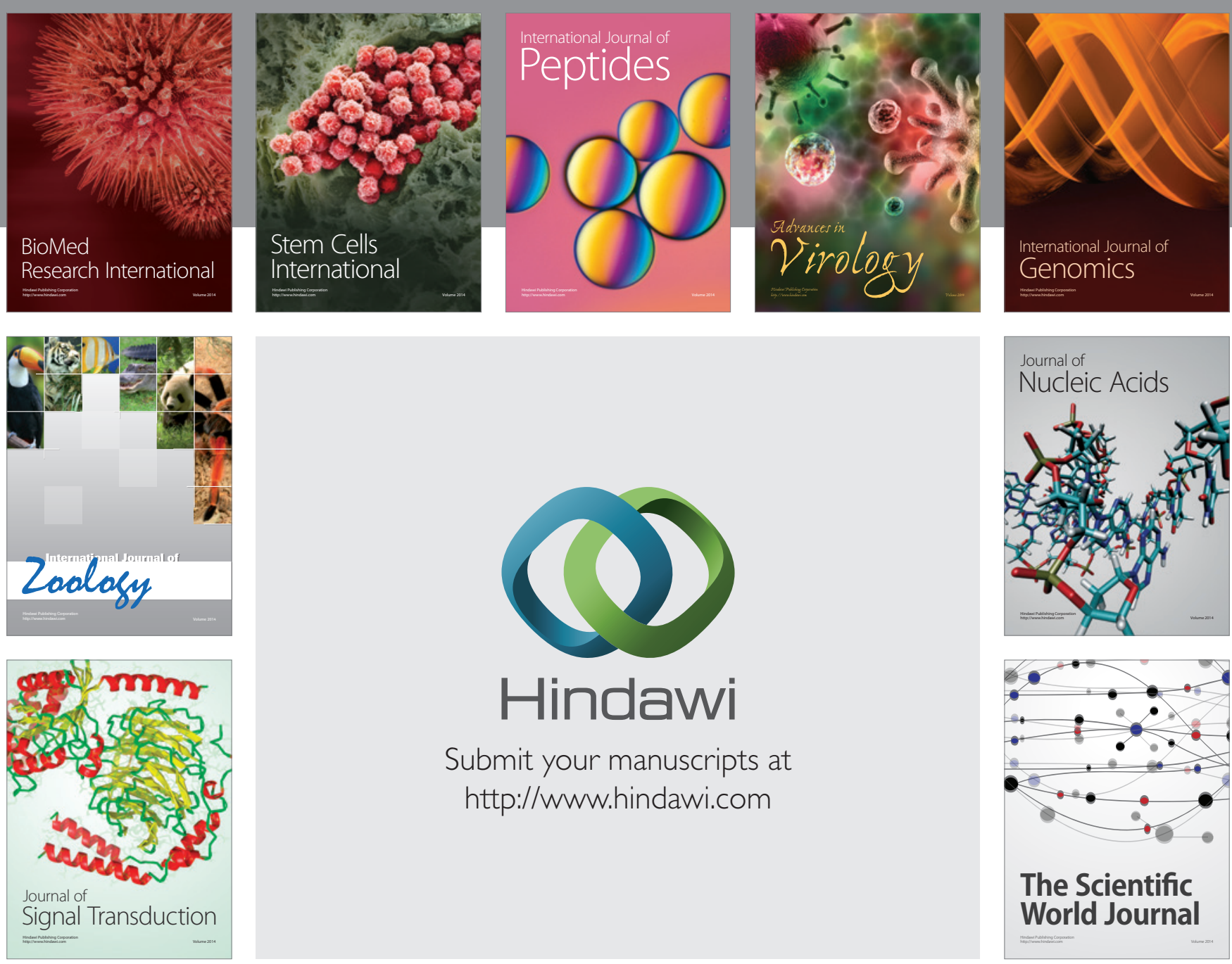

Submit your manuscripts at

http://www.hindawi.com
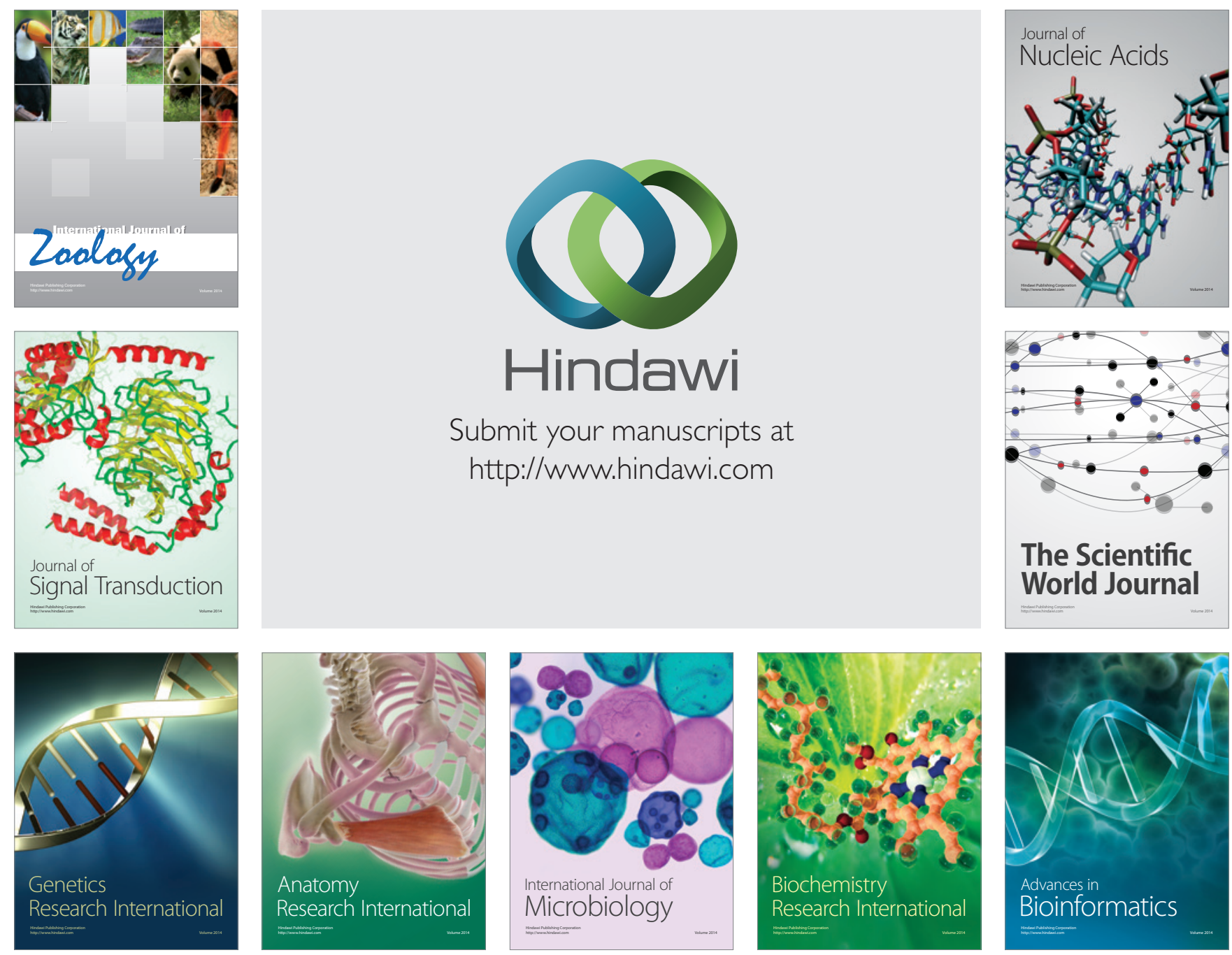

The Scientific World Journal
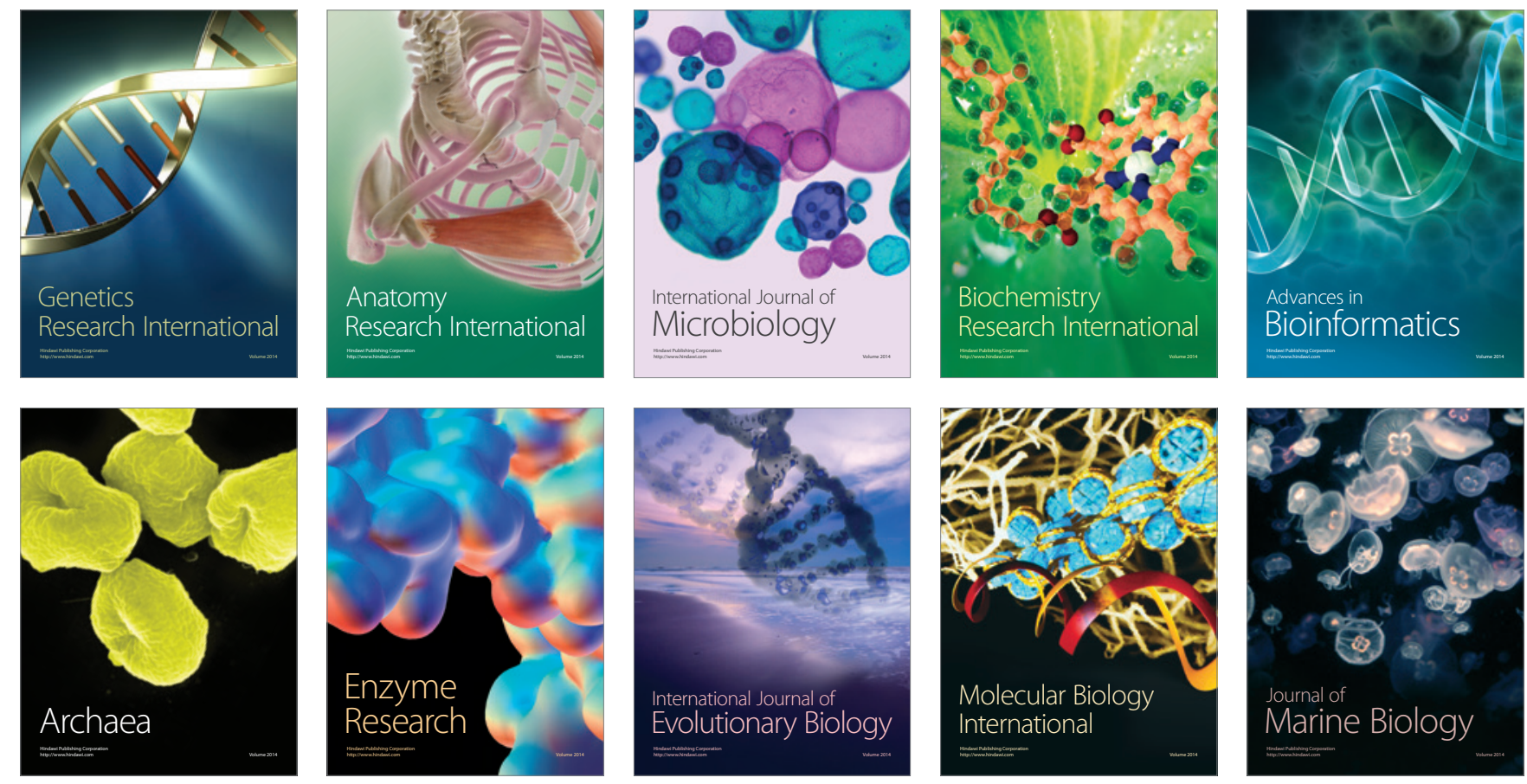